\title{
Significant delayed aortic dilatation after tetralogy of Fallot repair: a case report
}

\author{
Yosuke Nishimura $^{1 *}$ (D), Toru Yasutsune ${ }^{1}$, Shohei Shimajiri ${ }^{2}$, Yuki Jinzai ${ }^{1}$, Eigo Ikushima ${ }^{1}$, Takehiro Kishigami ${ }^{1}$ and \\ Tomoya Takigawa ${ }^{1}$
}

\begin{abstract}
Background: Aortic dilatation may occur in some patients even after complete repair of tetralogy of Fallot (TOF). The progression rate of the aortic diameter is so slow, and the incidence of aortic dissection is so low that it is suspected that frequent imaging of the aorta may not be necessary.

Case presentation: We describe an asymptomatic 41-year-old man with hypertension in whom aortic dilatation was accidentally discovered 39 years after TOF repair. He underwent ambulatory follow-up without any difficulty for 21 years after the repair. Contrast-enhanced computed tomography revealed significant aortic dilatation (maximum diameter of $88 \mathrm{~mm}$ at the sinus of Valsalva), and echocardiography revealed severe aortic regurgitation, which seemed to progress during the last 18 years without any evaluation or follow-up. The Bentall procedure was successfully performed using a valved graft, under deep hypothermic circulatory arrest with antegrade cerebral perfusion, and his postoperative course was uneventful. Histopathological examination of ascending aorta specimens revealed severe cystic medial degeneration.
\end{abstract}

Conclusions: Keeping in mind that a patient with rapid progression of the aortic dilatation after TOF repair exist, periodic follow-up for evaluation of the aorta is essential in patients with TOF.

Keywords: Aortic dilatation, Aneurysm, Tetralogy of Fallot

\section{Introduction}

Total repair of tetralogy of Fallot (TOF) is a safe procedure routinely performed to treat congenital heart disease; the Japanese Association for Thoracic Surgery reported an operative mortality rate of only $0.8 \%$ (3 patients) among 375 patients who underwent TOF repair in 2016 [1]. Despite the excellent operative outcomes of TOF repair, many patients develop arrhythmia and reoperations are necessary to treat complications including pulmonary regurgitation or stenosis, or residual ventricular septal defect (VSD) [2]. Aortic root dilatation and aneurysm may occur in patients after TOF repair; these complications are attributable to an intrinsic mechanism or a

\footnotetext{
* Correspondence: y-nishi@clnc.uoeh-u.ac.jp

'Department of Cardiovascular Surgery, School of Medicine, University of Occupational and Environmental Health, 1-1, Iseigaoka, Yahatanishi-ku, Kitakyushu 807-8555, Japan

Full list of author information is available at the end of the article
}

secondary effect of increased volume overload of the aorta caused by right-to-left shunting [3-6]. Chowdhury et al. reported that approximately $75 \%$ of patients with TOF showed histopathological abnormalities of the aortic wall, such as elastic lamellar fragmentation, increased ground substance, medial necrosis, and smooth muscle disarray, since infancy and that these changes were more pronounced in older patients [7]. Although aortic medial degeneration is less extensive and less severe in TOF patients than in those with Marfan syndrome [3, 8], the risk of aortic dilatation is much higher in patients with histopathologically proven aortic abnormalities [7].

Reportedly, the incidence of aortic dilatation defined by various criteria in patients who underwent TOF repair was 14-69\% [4-6], and risk factors for aortic dilatation after TOF repair were male sex, smoking, and late age at complete surgical repair $[5,6]$. However, the number of patients who underwent aortic operations

\section{Springer Open}

(c) The Author(s). 2020 Open Access This article is licensed under a Creative Commons Attribution 4.0 International License, which permits use, sharing, adaptation, distribution and reproduction in any medium or format, as long as you give appropriate credit to the original author(s) and the source, provide a link to the Creative Commons licence, and indicate if changes were made. The images or other third party material in this article are included in the article's Creative Commons licence, unless indicated otherwise in a credit line to the material. If material is not included in the article's Creative Commons licence and your intended use is not permitted by statutory regulation or exceeds the permitted use, you will need to obtain permission directly from the copyright holder. To view a copy of this licence, visit http://creativecommons.org/licenses/by/4.0/. 
after TOF repair was very low. A multicenter Japanese study reported the 236 patients $(5.9 \%)$ of 4010 patients who underwent TOF repair required reoperation, and only 4 patients $(0.1 \%)$ underwent reoperation to treat aortic dilatation [9]. Egbe et al. reported that among consecutive 453 patients who underwent TOF repair (the mean age was $37 \pm 13$ years), aortic dilatation occurred in 312 patients (69\%), and progressive aortic dilatation (defined as an increase $\geqq 2 \mathrm{~mm}$ in aortic dimensions) occurred in 40 patients (9\%). However, no patient developed aortic dissection, and only 7 patients $(1.5 \%)$ among them in whom the maximum diameter of aortic root or ascending aorta was more than $45 \mathrm{~mm}$ required prophylactic aortic procedures [4]. Kay et al. performed serial studies using magnetic resonance angiography in 55 patients and reported a slow rate of growth of $0.4 \pm 0.9 \mathrm{~mm} /$ year at the sinuses of Valsalva and $0.1 \pm 0.8 \mathrm{~mm} /$ year at the ascending aorta [5].

Notably, the incidence of aortic dissection and aneurysm rupture in patients undergoing TOF repair is quite low. To date, no retrospective observational studies have reported aortic dissection in patients undergoing TOF repair $[2,4-6,9,10]$. A search of the available literature yielded only 4 case reports describing aortic dissection in patients undergoing TOF repair [11-14]. All 4 cases of dissection were Stanford type A and occurred at aortic dimensions of $70 \mathrm{~mm}$ or greater. Records obtained from the National Inpatient Sample Database from 2000 to 2014 show that among hospital admissions of 18,353 adults TOF, only $11(0.06 \%)$ were thoracic aortic dissection related admissions (in-hospital mortality was $45 \%$ ), of which aortic surgical interventions were performed during 8 of the admissions [15]. The risk factors associated with aortic dissection in patients with TOF include male sex, age, and hypertension [15]. Studies have shown that moderately aortic dilatation may occur in patients undergoing TOF repair; however, this condition does not require frequent aortic imaging and early prophylactic surgical intervention because the incidence of aortic dissection in this patient population is very low in contrast to that observed in patients with degenerative and bicuspid aortic valve aortopathies $[4,5,10]$.

We describe a patient who underwent TOF repair with significant and rapid aortic root and ascending aorta dilatation of which the maximum diameter reached 88 $\mathrm{mm}$ at the level of sinuses of Valsalva during the last 18 years without any periodic follow-up or evaluation.

\section{Case}

An asymptomatic 41-year-old man underwent evaluation for employment health assessment and was accidentally discovered to have significant aortic dilatation. He reported a history of total repair of TOF with transannular patching at 2 years of age. Postoperatively, he underwent ambulatory follow-up for 21 years without any difficulty until he discontinued follow-up on his own because he was asymptomatic. Last transthoracic echocardiography (TTE) reports in his pediatric medical records at that time showed only trivial aortic regurgitation (AR) without any aortic root abnormality. On physical examination, he was $173 \mathrm{~cm}$ tall, weighed $65.6 \mathrm{~kg}$, and his blood pressure was elevated to $165 / 60 \mathrm{mmHg}$; however, he had not received any medication. Contrast-enhanced computed tomography $(\mathrm{CT})$ revealed significant aneurysmal aortic dilatation (maximum diameter of $88 \mathrm{~mm}$ at the sinus of Valsalva) (Fig. 1). TTE revealed severe AR, without significant pulmonary regurgitation or residual VSD, and transesophageal echocardiography showed a slight shortening of the noncoronary cusp and poor coaptation of leaflets of the aortic valve at the central portion where a massive AR, which had $0.9 \mathrm{~cm}^{2}$ of regurgitant orifice area, could be seen. Cardiac magnetic resonance imaging revealed that significant pulmonary regurgitation flow and residual VSD could not be detected and that right ventricular (RV) ejection fraction was $37 \%$, end-diastolic RV volume index was $201 \mathrm{ml} / \mathrm{m}^{2}$. He was referred to our department for surgical treatment of aortic root dilatation and AR.

The procedure was performed through a midline sternotomy, after taping the left femoral artery and vein. Cardiopulmonary bypass was established after femoral arterial and bicaval cannulation. Left ventricular venting was initiated using a venting tube inserted through the right upper pulmonary vein. Exacerbation of AR and onset of ventricular fibrillation were observed after initiation of cooling, necessitating aortic clamping, and antegrade cardioplegic arrest. Inspection through the aortotomy revealed a dilatated aortic annulus (diameter $35 \mathrm{~mm}$ ) and floppy aortic annulus and leaflets. All leaflets were thin and flail, and had irregular thickening which implied myxomatous degeneration. There was a stiff portion in the left ventricular outflow tract under the noncoronary and right coronary sinus, as a result of the VSD patch. Because we considered that valve-sparing aortic root replacement (VSARR) could be difficult, we performed the Bentall procedure using a 27-mm SJM Masters series Aortic Valved Graft (St. Jude Medical, Cardiology Division Inc., Minnesota), using felt strips in order to reinforce the aortic annulus. After cooling below $20^{\circ} \mathrm{C}$, we performed distal aortic anastomosis using a $28-\mathrm{mm}$ J-Graft Shield Noe $(27 \mathrm{~mm}$ ) (Japan Lifeline Co. Ltd., Japan) under deep hypothermic circulatory arrest with antegrade cerebral perfusion. After graft-to-graft anastomosis was performed, the patient was easily weaned from the bypass and showed an uneventful course except for the onset of ventricular fibrillation, which was controlled after short-termed assisted circulatory support. 


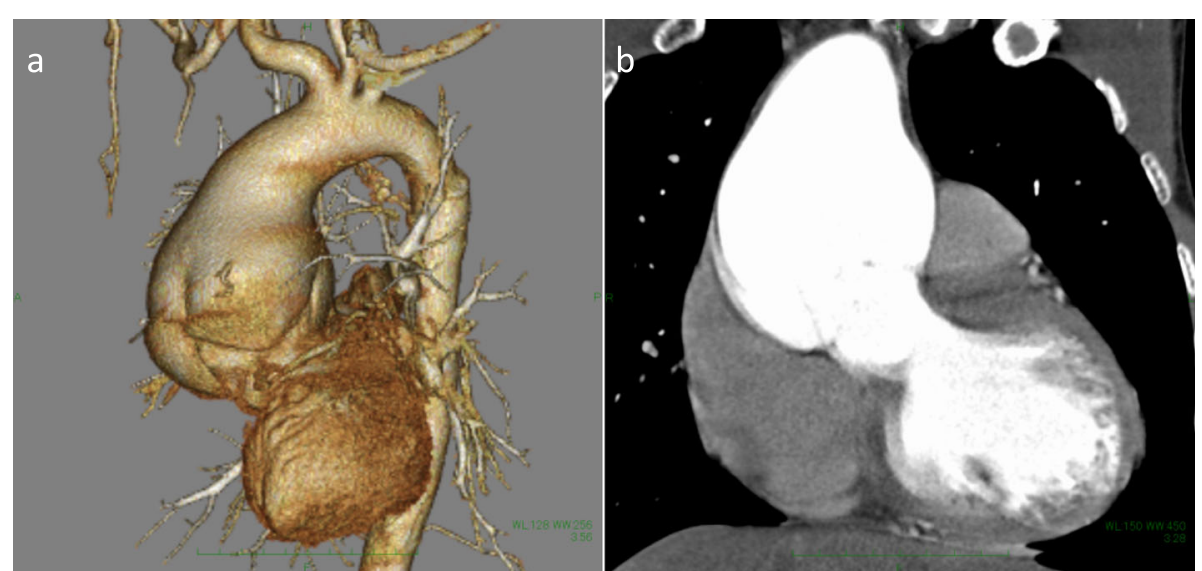

Fig. 1 Contrast-enhanced computed tomography scan showing a significantly dilatated aortic root and ascending aorta. Aortic aneurysm was located in the ascending aorta (a), and the maximum diameter of the aortic aneurysm is $88 \mathrm{~mm}$ at the sinus of Valsalva (b)

Histopathological examination of the ascending aorta specimens revealed cystic medial degeneration with some areas of mucopolysaccharides accumulation, collagen deposition, fragmentation, and loss of elastic lamellae across large areas of the media (Fig. 2a-c). The aortic valve showed mucoid degeneration with fragmentation of elastic fibers (Fig. 2d). The patient's postoperative course was uneventful, and he was discharged on the 26th postoperative day.

\section{Discussion}

This case received total repair of TOF at 2 years of age, which is not so late age, and underwent ambulatory follow-up without any difficulty including aortic dilatation until 23 years old. We concluded that his aortic diameter had rapidly increased over the last 18 years of adulthood. Unfortunately, he was not evaluated during this time, and his condition remained undetected. Although our patient did not develop aortic dissection, his aortic root showed significant dilatation and histological change of cystic medial degeneration with severe fragmentation and loss of elastic lamellae, which indicate a high-risk patient for aortic dissection. It is unclear that he had histopathological changes in his aortic wall at the first operation due to a lack of histopathological examinations at that time. Aortic dilatation and aneurysm are

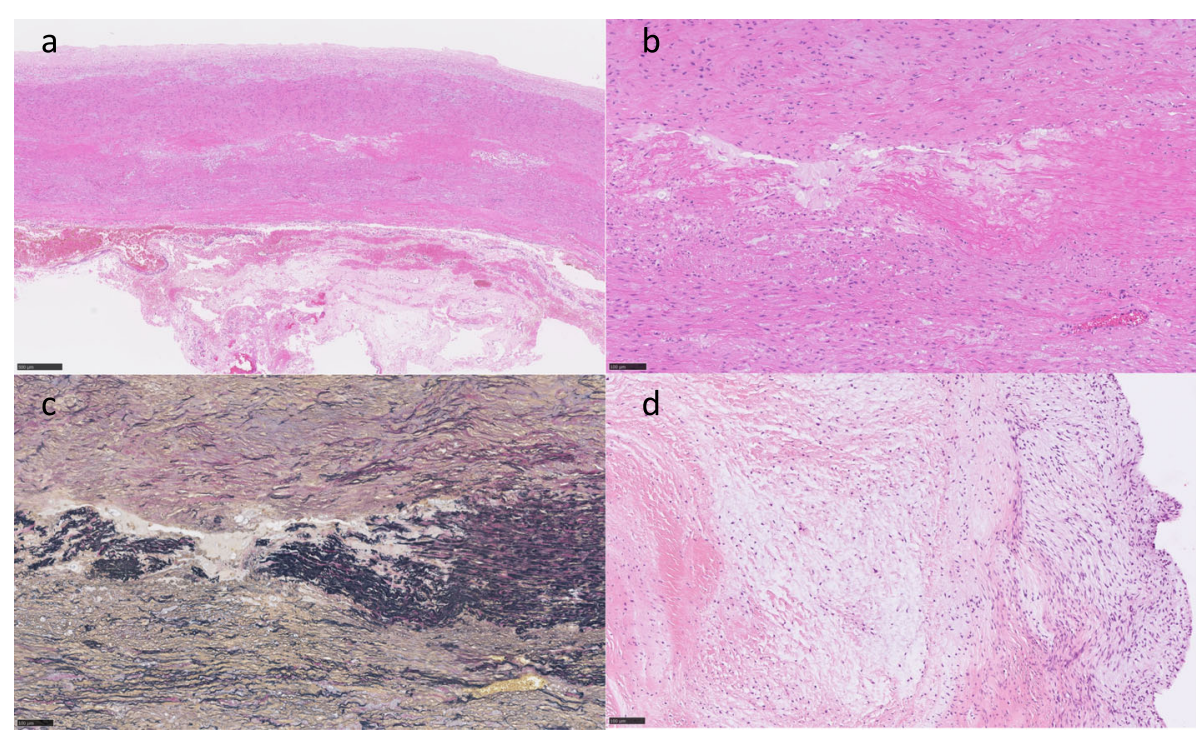

Fig. 2 Photomicrographs of the ascending aorta (a-c) and aortic valve (d) in the patients described in this report. Degeneration of the aorta with significant medial destruction and changes in smooth muscle orientation are observed in addition to accumulation of mucopolysaccharides and collagen deposition ( $\mathbf{a} \times$ 50 and $\mathbf{b} \times 200$, hematoxylin and eosin stain). Fragmentation and loss of elastic lamellae are observed across large areas of the media (c, elastica van Gieson stain $\times 200$ ). Mucoid degeneration of the aortic valve is clearly visualized (d, hematoxylin and eosin stain $\times 200$ ) 
attributable to an intrinsic mechanism or a secondary effect of increased volume overload of the aorta caused by right-to-left shunting [3-6]. We hypothesize that his aortic dilatation, after adulthood, can be attributed to hypertension, though his history of hypertension is unclear.

Recently, VSARR is reported to be effective for patients with aortic root dilatation and AR not only after repair of congenital heart disease [16, 17], but also with unrepaired TOF [18]. This procedure does not require long-term anti-coagulation therapy because it does not require the use of a mechanical valve and is suitable for young adult patients. Although satisfactory long-term results are reported, the recurrence of AR is one of the problems of this procedure $[16,17]$. The presence of more than moderate AR preoperatively has been suggested to be a risk factor for aortic valve durability [16]. The patients with previous repairs of congenital heart disease were considered to have some difficulties such as inherent anatomical abnormality, presence of VSD patch of previous operation, and adhesion due to previous operation. We thought that this case would be a difficult case for VSARR due to the severity of the AR and significant aortic annulus dilatation. Intraoperative inspection revealed that the aortic annulus and leaflets were very thin and floppy. All leaflets were thought to be myxomatous degeneration because of their irregular surface, which was determined with histopathological findings (Fig. 2d). In addition, we could find stiff portions, which seemed to be the VSD patch, just below the floppy annulus. We were afraid that the annulus could be deformed by an annular reduction procedure. We chose the Bentall procedure and reinforced the flail annulus using a felt strip. This frailty seemed unusual in comparison with general annuloaortic ectasia, but it is unclear whether it is a result of extremely dilatated aorta or a characteristic of patients with TOF. If this patient had been diagnosed earlier, when the aortic dilatation and AR were milder, he might be able to have more possibility to receive VSARR.

\section{Conclusion}

We report the case of significant aortic dilatation after TOF repair who showed a rapid increase in aortic diameter after adulthood. Despite the quite low incidence of aortic dissection and very slow growth rate of aortic diameter in general, this case emphasizes the importance of periodic follow-up for proper evaluation of the aorta in patients with TOF, even into adulthood, particularly in male patients with hypertension.

\section{Abbreviations}

TOF: Tetralogy of Fallot; VSD: Ventricular septal defect; TTE: Transthoracic echocardiography; AR: Aortic valve regurgitation; CT: Computed tomography; RV: Right ventricular; VSARR: Valve-sparing aortic root replacement

\section{Acknowledgements}

Not applicable.

\section{Authors' contributions}

YN drafted the manuscript. SS, TY, YJ, El, TK, and TT participated in its design and coordination and helped to draft the manuscript. SS evaluated

histological examination. The authors approved the final manuscript.

\section{Funding}

This research was not funded.

\section{Availability of data and materials}

The data are not available for public access because of patient privacy concerns but are available from the corresponding author on reasonable request.

\section{Ethics approval and consent to participate}

This study was conducted in accordance with the ethical standards of our institute.

\section{Consent for publication}

Informed consent was obtained from the patient for the publication of this case report.

\section{Competing interests}

All authors declare that they have no competing interests.

\section{Author details}

'Department of Cardiovascular Surgery, School of Medicine, University of Occupational and Environmental Health, 1-1, Iseigaoka, Yahatanishi-ku, Kitakyushu 807-8555, Japan. ${ }^{2}$ Department of Surgical Pathology, School of Medicine, University of Occupational and Environmental Health, 1-1, Iseigaoka, Yahatanishi-ku, Kitakyushu 807-8555, Japan.

Received: 6 May 2020 Accepted: 7 July 2020

Published online: 17 July 2020

\section{References}

1. Shimizu H, Endo S, Natsugoe S, Doki Y, Hirata Y, Kobayashi, et al. Thoracic and cardiovascular surgery in Japan in 2016: annual report by the Japanese Association for Thoracic Surgery. Committee for Scientific Affairs, The Japanese Association for Thoracic Surgery. Gen Thorac Cardiovasc Surg. 2019;67(4):377-411.

2. Cuypers JA, Menting ME, Konings EE, Opić P, Utens EM, Helbing WA, et al. Unnatural history of tetralogy of Fallot: prospective follow-up of 40 years after surgical correction. Circulation. 2014;130(22):1944-53.

3. Niwa K. Aortic dilatation in complex congenital heart disease. Cardiovasc Diagn Ther. 2018;8(6):725-38.

4. Egbe AC, Miranda WR, Ammash NM, Anavekar NS, Missula VR, Kothapalli S, et al. Aortic disease and interventions in adults with tetralogy of Fallot. Heart. 2019;105(12):926-31.

5. Kay WA, Cook SC, Daniels CJ. Evaluation by MRA of aortic dilation late after repair of tetralogy of Fallot. Int J Cardiol. 2013;167(6):2922-7.

6. Mongeon FP, Gurvitz MZ, Broberg CS, Aboulhosn J, Opotowsky AR, Kay JD, et al. Aortic root dilatation in adults with surgically repaired tetralogy of Fallot: a multicenter cross-sectional study. Circulation. 2013;127(2):172-9.

7. Chowdhury UK, Mishra AK, Ray R, Kalaivani M, Reddy SM, Venugopal P. Histopathologic changes in ascending aorta and risk factors related to histopathologic conditions and aortic dilatation in patients with tetralogy of Fallot. J Thorac Cardiovasc Surg. 2008;135(1):69-77.

8. Niwa K, Perloff JK, Bhuta SM, Laks H, Drinkwater DC, Child JS, et al. Structural abnormalities of great arterial walls in congenital heart disease: light and electron microscopic analyses. Circulation. 2001;103(3):393-400.

9. Mizuno A, Niwa K, Matsuo K, Kawada M, Miyazaki A, Mori Y, et al. Survey of reoperation indications in tetralogy of Fallot in Japan. Circ J. 2013;77(12): 2942-7.

10. Stulak JM, Dearani JA, Burkhart HM, Sundt TM, Connolly HM, Schaff HV. Does the dilated ascending aorta in an adult with congenital heart disease require intervention? J Thorac Cardiovasc Surg. 2010; 140(6 Suppl): S52-S57; discussion S86-91. 
11. Kim WH, Seo JW, Kim SJ, Song J, Lee J, Na CY. Aortic dissection late after repair of tetralogy of Fallot. Int J Cardiol. 2005;101(3):515-6.

12. Rathi VK, Doyle M, Williams RB, Yamrozik J, Shannon RP, Biederman RW. Massive aortic aneurysm and dissection in repaired tetralogy of Fallot; diagnosis by cardiovascular magnetic resonance imaging. Int J Cardiol. 2005;101(1):169-70.

13. Wijesekera VA, Kiess MC, Grewal J, Chow R, Raju R, Leipsic JA, et al. Aortic dissection in a patient with a dilated aortic root following tetralogy of Fallot repair. Int J Cardiol. 2014;174(3):833-4.

14. Konstantinov IE, Fricke TA, d'Udekem Y, Robertson T. Aortic dissection and rupture in adolescents after tetralogy of Fallot repair. J Thorac Cardiovasc Surg. 2010;140(5):e71-3.

15. Egbe AC, Crestanello J, Miranda WR, Connolly HM. Thoracic aortic dissection in tetralogy of Fallot: a review of the National Inpatient Sample Database. J Am Heart Assoc. 2019; 19: 8(6): e011943. DOl: https://doi.org/10.1161/ JAHA119.011943.

16. Baliulis G, Ropponen JO, Salmon TP, Kaarne MO. Valve-sparing aortic root replacement in adult patients previously operated for congenital heart defects: an initial experience. Eur J Cardiothorac Surg. 2016;50(1):155-9.

17. Vricella LA, Cameron DE. Valve-sparing aortic root replacement in pediatric patients: lessons learned over two decades. Semin Thorac Cardiovasc Surg Pediatr Card Surg Annu. 2017:20:56-62.

18. Adachi O, Suzuki T, Yoshioka I, et al. Concomitant valve-sparing aortic root replacement with repair of tetralogy of Fallot. Ann Thorac Surg. 2019;108(2): e99-e101.

\section{Publisher's Note}

Springer Nature remains neutral with regard to jurisdictional claims in published maps and institutional affiliations.

\section{Submit your manuscript to a SpringerOpen ${ }^{\circ}$ journal and benefit from:}

- Convenient online submission

- Rigorous peer review

- Open access: articles freely available online

- High visibility within the field

- Retaining the copyright to your article

Submit your next manuscript at $\boldsymbol{\nabla}$ springeropen.com 